Article

\title{
Comparison of Oxidative Status of Human Milk, Human Milk Fortifiers and Preterm Infant Formulas
}

\author{
Luisa Pozzo $^{1}$, Simona Cirrincione ${ }^{2, *}$, Rossella Russo ${ }^{1}$, Magdalena Karamać ${ }^{3}$ (D), \\ Ryszard Amarowicz ${ }^{3}{ }^{(D)}$, Alessandra Coscia ${ }^{4}$, Sara Antoniazzi ${ }^{2}$, Laura Cavallarin ${ }^{2} \mathbb{D}$ and \\ Marzia Giribaldi ${ }^{5}$ (D)
}

1 Institute of Agricultural Biology and Biotechnology, National Research Council, 56124 Pisa, Italy; luisa.pozzo@ibba.cnr.it (L.P.); rossella.wilbur@gmail.com (R.R.)

2 Institute of Sciences of Food Production, National Research Council, 10095 Grugliasco (TO), Italy; sara.antoniazzi@ispa.cnr.it (S.A.); laura.cavallarin@ispa.cnr.it (L.C.)

3 Institute of Animal Reproduction and Food Research, Polish Academy of Sciences, 10748 Olsztyn, Poland; m.karamac@pan.olsztyn.pl (M.K.); r.amarowicz@pan.olsztyn.pl (R.A.)

4 Neonatal Intensive Care Unit, University of Torino, Città della Scienza e della Salute, 10126 Torino, Italy; alessandra.coscia@unito.it

5 Research Center for Engineering and Agro-Food Processing, Council for Agricultural Research and Economics, 10035 Torino, Italy; marzia.giribaldi@crea.gov.it

* Correspondence: simona.cirrincione@ispa.cnr.it; Tel.: +39-011-6719231

Received: 6 August 2019; Accepted: 4 October 2019; Published: 8 October 2019

\begin{abstract}
Preterm and low birth weight infants require specific nutrition to overcome the accumulated growth deficit, and to prevent morbidities related to postnatal growth failure. In order to guarantee an adequate nutrient-intake, mother's own milk, when available, or donor human milk, are usually fortified with additional nutrients, in particular proteins. Fortification with processed ingredients may result in additional intake in oxidative compounds, deriving from extensive heat treatments, that are applied during processing. The aim of the present work was to compare the in vitro antioxidant activity and oxidative compound content conveyed by different preterm infant foods and fortifiers, namely raw and pasteurized human milk, two different preterm infant formulas, three bovine milk-based fortifiers and two experimental donkey milk-based fortifiers. Univariate and multivariate statistical analyses revealed significant differences between the different products. The use of human milk minimizes the intake of dietary oxidative compound in comparison to infant formulas, irrespective of pasteurization or fortification, especially as far as malondialdehyde content is concerned. The addition of fortifiers to human milk increases its antioxidant capacity, and the choice of the protein source (hydrolysed vs. whole proteins) differently impacted the resulting total antioxidant capacity of the diet.
\end{abstract}

Keywords: donkey milk; human milk; infant formulas; protein fortifiers; malondialdehyde; TEAC

\section{Introduction}

Preterm infants, including extremely and very low birth weight (LBW) infants, are known to have higher nutritional requirements than term infants [1,2]. For all infants, the mother's own milk is considered the best first feeding choice, as recommended by the World Health Organization, by the European Society for Pediatric Gastroenterology Hepatology and Nutrition, and by the American Academy of Pediatrics [3]. Human milk contains a variety of bioactive compounds that are involved in the shaping and modulation of the gastrointestinal tract and immune system, as well as in brain development, in addition to its nutrient composition $[3,4]$. 
An appropriate nutrition constitutes a prominent factor for a good quality of life during childhood and adulthood. Several disorders are due to nutrient deficiency in the first months of life. For preterm infants, low sodium level may lead to hyponatraemia, and calcium and phosphorus intake could be below the intake needed to achieve foetal rates of bone mineral accretion [1,2,5-7]. For preterm and LBW infants, an adequate protein intake is crucial to limit post-natal growth deficit; after the first weeks, the protein content of human milk is too low to ensure adequate growth. Considering that the growth deficit is difficult to recover during the unstable phase, the feeding of clinically stable preterm infants becomes crucial to recuperate the accumulated deficit, and to prevent morbidities related to postnatal growth failure. Therefore, supplementation of human milk (HM) with more than one nutritional component is a common practice in most neonatal intensive care units (NICUs) [3].

Since mothers' own milk has been acknowledged as the gold standard in infant nutrition, industrial strategies have been directed toward mimicking the nutritional profile of human breast milk for optimizing infant growth and development. Protein-based fortifiers for human milk and preterm infant formulas (PIF) are being continuously improved by manufacturers, to cope with new nutritional trends and recommendations for adequate preterm growth. The source and/or the quality of both the protein and lipid fractions of preterm infant formulas and supplements may have important consequences on tolerability, palatability, allergenicity and nutritional outcomes. For protein-based fortifiers, bovine milk constituents (caseins, whey proteins and hydrolysates thereof) are the most common sources of nitrogen. Plant oils (such as palm, sunflower and coconut) and fish oils are usually added as a fat source $[8,9]$. Carbohydrate sources are mostly represented by lactose and maltodextrins (corn syrup solids). In addition, a variety of vitamins, mineral mixes, and other ingredients are added, depending on the manufacturer, although beneficial claims associated with some ingredients are often largely to be demonstrated [10]. Besides macro and micronutrients, the presence of bioactive compounds with possible health benefits, as well as that of contaminants deriving from food alteration, should be carefully evaluated. To ensure microbiological safety and long shelf life, preterm infant formulas usually undergo extensive heat treatment at high temperatures. For this reason, and due to their high concentration of nutrients, preterm infant formulas and fortifiers are more prone to thermally induced degradation reactions than standard milk products. In particular, lipid and protein modifications, occurring as a consequence of product manufacturing, may adversely affect the quality of food products intended for preterm infants, and may increase the intake in oxidative and oxidized compounds [11-13]. An increase in antioxidant supply, as well as a reduced oxidized species intake, is specifically relevant for preterm infants, which have an immature antioxidant defence system and are frequently exposed to oxidative stress caused by infection, mechanical ventilation, intravenous nutrition, and blood transfusions $[14,15]$. Previous studies have reported the quantification of biomarkers derived from oxidation processes, such as malondialdehyde (MDA), isoprostanes and protein carbonyls, as a reliable strategy for the evaluation of in vivo oxidative stress in preterm newborn [16-18].

In recent years, innovative efforts have been made to provide the best compromise between the nutritional needs of preterm infants and the maximum intake in bioactive compounds. Fortifiers based on human milk proteins $[19,20]$ and on donkey milk [21,22] have been studied as an alternative to bovine milk-based fortifiers, and, in the case of human milk-based fortifiers, commercialized. A HM based fortifier has been demonstrated to decrease the duration of parenteral nutrition and to reduce rates of necrotizing enterocolitis $[19,20]$. In a recently published clinical trial, a new donkey milk-derived fortifier brought about a reduction in feeding intolerance, bilious gastric residuals and vomiting in hospitalized preterm and LBW infants [21]. In all the aforementioned studies, the use of breast milk was recognized as the best nutritional strategy in preterm newborn nutrition.

The aim of this work is to compare the biochemical composition of 9 products for preterm infant nutrition (human milk, preterm infant formulas (PIFs), multicomponent fortifiers and protein concentrates), with specific focus on in vitro antioxidant activity and content in oxidative compounds. 


\section{Materials and Methods}

\subsection{Bovine Milk-Based Infant Formulas and Human Milk Fortifiers}

Four commercially available bovine milk-based products for preterm infant nutrition-two PIFs (Prenidina and Plasmon 0) and two multicomponent fortifiers for human milk (FM85 and Milte) and one protein concentrate (Protifar) - were considered. Liquid products were lyophilized before analysis, and stored at $-20^{\circ} \mathrm{C}$.

\subsection{Donkey Milk-Based Human Milk Fortifiers}

Two experimental donkey milk (DM)-based fortifiers were produced on a pilot scale. The two experimental DM-based human milk fortifiers were produced by ultrafiltration of pasteurized donkey milk. The ultrafiltration process was designed to obtain two different fortifiers, characterized by two protein concentration levels, comparable to the corresponding bovine milk derived commercial products (FM85 and Milte). Protein concentrates were pasteurized, aseptically lyophilized and packed, and analysed to ensure compliance to microbiological criteria for infant food products. The two experimental DM-based products were used in a clinical trial, as previously described [21,22].

\subsection{Raw and Pasteurized Human Milk}

Both raw and pasteurized HM samples were obtained from the human milk bank (HMB) of the Città della Scienza e della Salute of Torino, Italy, from 4 healthy donor mothers. All mothers were enrolled as donors by the bank, and donations were performed in accordance with the HMB guidelines. An ethical review process was not required for this study. At first donation, donors signed a written informed consent, and were informed that only milk samples stored in excess of the needs of their infants would have been used for research purposes. The milk specimens from term mothers were collected in sterile bisphenol-free polypropylene bottles using a breast pump and stored, by the HMB, at $-20^{\circ} \mathrm{C}$ until processed. The HM samples were thawed overnight in a refrigerator, and pooled before pasteurization and lyophilisation. Half of the pooled sample was pasteurized in the HMB facility at $62.5^{\circ} \mathrm{C}$ for $30 \mathrm{~min}$ (holder pasteurization) before lyophilisation. The raw (RHM) and pasteurized samples (DHM) were finally lyophilized, to increase the stability of samples, without modifying the nutritional properties, the content of oxidised species and enzymatic activities of human milk [23,24].

\subsection{Chemical Composition Determination for Experimental Products and Human Milk Samples}

The chemical composition of experimental products and human milk samples was determined in terms of gross energy, lactose, total protein and fat content. Gross energy was determined in excess oxygen by adiabatic bomb calorimeter (Mod. 700, IKA GmbH \& Co., Staufen, Germany), using benzoic acid as a reference $(26.454 \mathrm{MJ} / \mathrm{kg}$ ). Protein concentration was determined by UV spectroscopy at $280 \mathrm{~nm}$ using bovine serum albumin as standard, and by the Dumas method using a RapidN III device (Elementar Analysensysteme GmbH e Isoprime Ltd, Lomazzo, Co, Italy). The total fat content was measured gravimetrically on ether extract after acid hydrolysis according to the ISTISAN method A [25]. Lactose content was measured by enzymatic assay kit (R-Biopharm AG, Darmstadt, Germany).

\subsection{Trolox Equivalent Antioxidant Capacity (TEAC)}

The Trolox (6-hydroxy-2,5,7,8-tetramethylchroman-2-carboxylic acid) equivalent antioxidant capacity (TEAC) of aqueous suspensions from preterm foods and supplements $(50 \mathrm{mg} / \mathrm{mL}$, and dilutions thereof, where necessary) was determined using the 2,2'-azino-bis(3-ethylbenzothiazoline-6-sulphonic acid) (ABTS) radical cation decolorization assay [26]. ABTS was activated in a $2.45 \mathrm{mmol} / \mathrm{L}$ solution of potassium persulfate for $16 \mathrm{~h}$. The stock solution was diluted with water up to a final absorbance of $0.70 \pm 0.02$ at $\lambda=734 \mathrm{~nm}$. The $\mathrm{ABTS}^{\bullet+}$ solution was pipetted in $2 \mathrm{~mL}$ doses to test tubes placed in a block heater (TH-24, Meditherm, Poland) warmed to $30{ }^{\circ} \mathrm{C}$, and, after temperature settling, 
$0.02 \mathrm{~mL}$ of tested suspensions were added. The absorbance was recorded at $\lambda=734 \mathrm{~nm}$ (DU-7500 spectrophotometer, Beckman, Brea, CA, USA) after centrifugation for $5 \mathrm{~min}$ at $4000 \times g$ (MiniSpin plus, Eppendrof, Hamburg, Germany). The results were calculated using a curve for Trolox as reference, and expressed as $\mu \mathrm{mol}$ Trolox equivalents per $100 \mathrm{~mL}$ (for liquid foods) or per $1 \mathrm{~g}$ of proteins (for protein fortifiers). For each milk sample type, fortifier and concentrate, three technical replicates were analysed.

\subsection{Antioxidant Activity Against DPPH}

Antiradical activity of aqueous resuspensions $(50 \mathrm{mg} / \mathrm{mL})$ against $\mathrm{DPPH}^{\bullet}$ (2,2-diphenyl-1-picrylhydrazyl radical) was measured according to the method described by Brand-Williams et al. [27]. The reaction was run by immediately vortexing $0.1 \mathrm{~mL}$ from each tested resuspension with $0.25 \mathrm{~mL}$ of $1 \mathrm{mmol} / \mathrm{L}$ methanolic solution of DPPH and $2 \mathrm{~mL}$ of methanol. After $20 \mathrm{~min}$, the reaction mixtures were centrifuged for $5 \mathrm{~min}$ at $4000 \times g$ (MiniSpin plus, Eppendrof, Hamburg, Germany) and absorbance was read at $\lambda=517 \mathrm{~nm}$ (DU-7500Beckman). Radical scavenging activity was expressed as the inhibition percentage of free radicals by the sample and was calculated as [1 - (test sample absorbance/DPPH ${ }^{\bullet}$ solution absorbance) $] \times 100$ [28], normalized over the different protein content for protein fortifiers and expressed on a $100 \mathrm{~mL}$ volume for liquid foods. For each milk sample type, fortifier and concentrate, three technical replicates were analysed.

\subsection{Measurement of Oxidative Content (Protein Carbonyls and Malondialdehyde)}

The protein carbonyl (PC) content was determined using the methodology adapted from Fenaille et al. [11] as previously reported [29]. An aliquot of aqueous resuspensions $(10 \mathrm{mg} / \mathrm{mL})$ was incubated with $10 \mathrm{mmol} / \mathrm{L}$ of 2,4-dinitrophenylhydrazine (DNPH) in $2 \mathrm{~mol} / \mathrm{L} \mathrm{HCl}$ (1 mL volume), for $30 \mathrm{~min}$ at room temperature. Proteins were then precipitated by adding $10 \%(w / v$, final concentration) trichloroacetic acid, and recovered by centrifugation for $5 \mathrm{~min}$ at $7500 \times \mathrm{g}$ (Micromax RF centrifuge, International Equipment Company, Needham, MA). Protein pellets were washed 3 times with $1 \mathrm{~mL}$ of ethanol/ethyl acetate 50:50 (v/v) to remove free DNPH reagent, and redissolved in $1 \mathrm{~mL}$ of $6 \mathrm{~mol} / \mathrm{L}$ guanidine hydrochloride, $\mathrm{pH}$ 2.3. Protein carbonyls were determined by UV spectrophotometry at $\lambda=370 \mathrm{~nm}$, using an extinction coefficient of $2.2 \times 10^{4} \mathrm{~L} \mathrm{~mol}^{-1} \cdot \mathrm{cm}^{-1}$, with a Mini Spec UV-vis spectrophotometer (Shimadzu, Kyoto, Japan). Results were reported as $\mu \mathrm{mol}$ of PC per $100 \mathrm{~mL}$ (for liquid foods) or per $1 \mathrm{~g}$ of proteins (for protein fortifiers). The content of MDA of preterm foods and supplements was analysed according to Seljeskog et al. [30], with some adaptations. Extracted samples were injected in the HPLC system consisted of a Dionex P680 pump (Dionex, Sunnyvale, CA, USA), a RF-2000 fluorimetric detector $\left(\lambda_{\mathrm{ex}}=525, \lambda_{\mathrm{em}}=560\right)$, a thermostated column compartment TCC-100, a ASI100 autosampler series and a Chromeleon $® 6$ data handling system (Dionex). The analytical column was a Gemini LC-18 column $(150 \times 4.6 \mathrm{~mm}, 5 \mu \mathrm{m}$ particles) (Phenomenex, Torrance, CA, USA) preceded by an Analytical Guard Cartridge System (Phenomenex). The system ran isocratically with a mobile phase containing $50 \mathrm{mmol} / \mathrm{L} \mathrm{KH}_{2} \mathrm{PO}_{4}$-methanol-acetonitrile $(72: 17: 11, v / v / v)$, at a flow rate of $0.8 \mathrm{~mL} / \mathrm{min}$. A standard curve was made from 1,1,3,3-tetraethoxypropane (TEP) dissolved in methanol and diluted at concentrations of 10.0, 5.0, 2.5, 1.25, 0.62 and $0.21 \mu \mathrm{mol} / \mathrm{L}$. Results were expressed as nmol MDA per $100 \mathrm{~mL}$ (for liquid foods) or per $1 \mathrm{~g}$ of proteins (for protein fortifiers). For each milk sample type, fortifier and concentrate, three technical replicates were analysed.

\subsection{In Vitro Antioxidant Activity}

Preparation of erythrocytes. According to the regulations of "Fondazione G. Monasterio CNR-Regione Toscana", human blood samples were collected from healthy blood donors upon informed consent, for the use of residual blood for research purposes. Samples of human blood from three healthy volunteers were collected in ethylenediaminetetracetic acid (EDTA)-treated tubes, and centrifuged (Jouan CR3i, Thermo Electron Corporation, UK), for $10 \mathrm{~min}$ at $2300 \times \mathrm{g}$ at $4{ }^{\circ} \mathrm{C}$. Plasma and buffy coat were discarded, and erythrocytes were washed twice with PBS at pH 7.4. 
Cellular antioxidant activity assay in red blood cells (CAA-RBC). The antioxidant activity of preterm foods and supplements was evaluated in an in vitro system with red blood cells (RBC) [31]. Erythrocytes were diluted 1:100 $(w / v)$ in PBS at $\mathrm{pH} 7.4$ and incubated for $1 \mathrm{~h}$ at $37{ }^{\circ} \mathrm{C}$ with $15 \mu \mathrm{mol} / \mathrm{L}$ of $2^{\prime}, 7^{\prime}$-dichlorodihydrofluorescein diacetate (DCFH-DA) and PBS (control) or tested samples (100 g/L water dissolved and diluted with PBS). At the end of the incubation, RBC were washed twice, resuspended in cold PBS and transferred to a 96-well microplate. After that, $1.2 \mathrm{mM}$ 2,2'-azobis(2-methylpropionamidine) dihydrochloride (AAPH) was added to the cell suspension and the fluorescence was read each 8 seconds for 12 cycles at $\lambda_{\mathrm{ex}}=485 \mathrm{~nm}$ and $\lambda_{\mathrm{em}}=535 \mathrm{~nm}$ by Victor ${ }^{\mathrm{TM}}$ 3 Multilabel Plate Reader (Waltham, MA) in order to generate a curve. Each value was expressed as CAA units, according to the Wolfe and Liu formula [32]:

$$
\text { CAA unit }=100-\left(\int \mathrm{SA} / \int \mathrm{CA}\right) \times 100
$$

where $\int \mathrm{SA}$ is the integrated area of the sample curve and $\int \mathrm{CA}$ is the integrated area of the control curve. Hemolysis test. Hemolysis was measured according to the method of Mikstacka et al. [33] using AAPH, a generator of peroxyl radicals, to induce RBC lysis. Briefly, $450 \mu \mathrm{L}$ of a $5 \%(w / v)$ erythrocyte suspension in PBS was pre-incubated with tested resuspensions of preterm foods and supplements $\left(100 \mathrm{~g} / \mathrm{L}\right.$ water) at $37^{\circ} \mathrm{C}$ for $1 \mathrm{~h}$, then exposed to $50 \mu \mathrm{L}$ of $50 \mathrm{mmol} / \mathrm{L}$ AAPH at $37^{\circ} \mathrm{C}$ for $4 \mathrm{~h}$. The samples were centrifuged (Jouan CR3i) for $5 \mathrm{~min}$ at $1000 \times \mathrm{g}$, and the absorbance was read at $\lambda=540 \mathrm{~nm}$. Control and blank samples were represented by erythrocytes pre-incubated only with AAPH or with PBS (blank). The values reported are the percentage of hemolysis compared to the control.

\subsection{Statistical Analysis}

In order to allow direct comparison among the different products under assay, data were expressed on a $100 \mathrm{~mL}$ volume basis of human milk (both raw and pasteurized) and reconstituted PIFs, while data from preterm fortifiers (both multicomponent and concentrate) where expressed per gram of protein. The statistical analyses of products expressed on volume basis and of those expressed per gram of protein were performed separately. Before analysis, data were standardized by subtracting mean values and dividing by standard deviations of each parameter, and subjected to one-way and multivariate analysis of variance and to hierarchical clustering. One-way ANOVA was performed by F-test followed by Tukey's post-hoc, or by the Kruskal-Wallis test followed by Dunn's post-hoc for, respectively, non-significant and significant Levene's test for homogeneity of variances. Multivariate ANOVA and hierarchical clustering (UPGMA algorithm of Manhattan distances) were performed by analyzing all standardized values. All statistical analyses were performed by the PAST 3 software package [34].

\section{Results and Discussion}

The infant foods and human milk fortifiers considered in the present research were selected to be representative of different sources of nutrients, on the basis of the manufacturers' labels (Table 1), with a focus on the protein source and status (whole or hydrolysed). In particular, we selected two PIFs, both containing bovine milk proteins, although differing in terms of the protein type. PIF1 contained whole caseins and whey proteins, with added lactoferrin, while PIF2 contained partially hydrolysed whey proteins. Both PIFs contained added docosahexaenoic acid (DHA), arachidonic acid (ARA) and medium-chain triacylglycerols (MCT), plant oils, maltodextrins and lactose. PIF1 also contained GOS as prebiotics. In addition, a human breast milk sample before (RHM) and after pasteurization (DHM) was considered. 
Table 1. Composition of commercial and experimental products used in the current study (source: manufacturers; "Latti formulati in commercio in Italia" by De Curtis M. and Gasparrini E.)

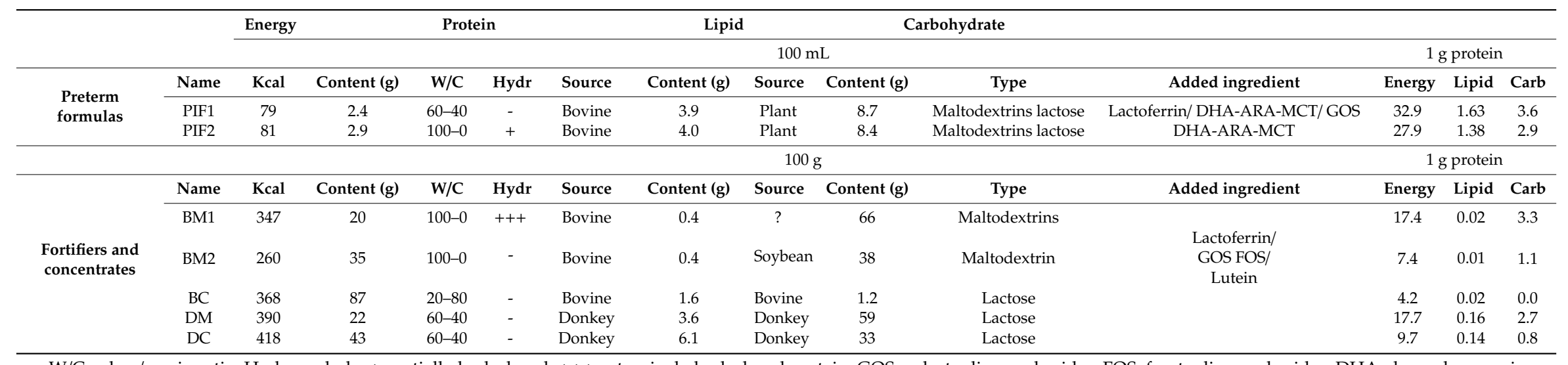

W/C: whey/casein ratio; Hydr:-whole; + partially hydrolysed; +++ extensively hydrolysed protein; GOS: galactooligosaccharides; FOS: fructooligosaccharides; DHA: docosahexaenoic acid; ARA: arachidonic acid; MCT: medium-chain triacylglycerols; PIF: preterm infant formula; BM: bovine milk-based fortifier; BC: bovine concentrate; DM: donkey milk-based fortifier; DC: donkey concentrate. 
Of the two considered bovine milk-based fortifiers (BM1 and BM2), BM1 contained extensively hydrolysed whey proteins and maltodextrins, while BM2 contained whole whey proteins, added lactoferrin, lutein and prebiotics (GOS and FOS). We also considered two experimental products derived from whole donkey milk, without added ingredients. A protein concentrate (85\% protein) derived from skimmed bovine milk (BC) was also sampled, containing whole caseins and whey proteins. The nutrient composition and the concentrations of measured oxidative status parameters were expressed as per gram of protein for the fortifiers and the protein concentrate, since the neonatal intensive care unit guidelines and the clinical practice indicate preterm infant requirements as $g$ of added protein per $1 \mathrm{~kg}$ of body weight per day. For human milk and reconstituted PIFs, the aforementioned parameters were expressed on a $100 \mathrm{~mL}$ volume basis, since the starting of fortification is advisable when enteral intake reaches $100 \mathrm{~mL} / \mathrm{kg} /$ day [4].

The analyses performed included 3 assay types aimed at determining the oxidative load of the samples by measuring: (i) the antioxidant activity/capacity, by measuring radical scavenging (TEAC, DPPH), (ii) the antioxidant activity/capacity, by using erythrocytes as indicators (Haemolysis, CAA-RBC), and (iii) quantification of intermediate/final oxidation products (MDA, PC). An overview of the differences between the samples was first performed by a multivariate approach, including all oxidative status parameters. Figure 1 reports the results of multivariate hierarchical clustering of samples PIFs, RHM and DHM. The clusters showed a higher similarity between PIF2 and human milk samples, with respect to PIF1, in term of oxidation status. Multivariate ANOVA revealed that the observed differences in the oxidative load (as measured by considering all the parameters together) were significant $(p<0.001)$.

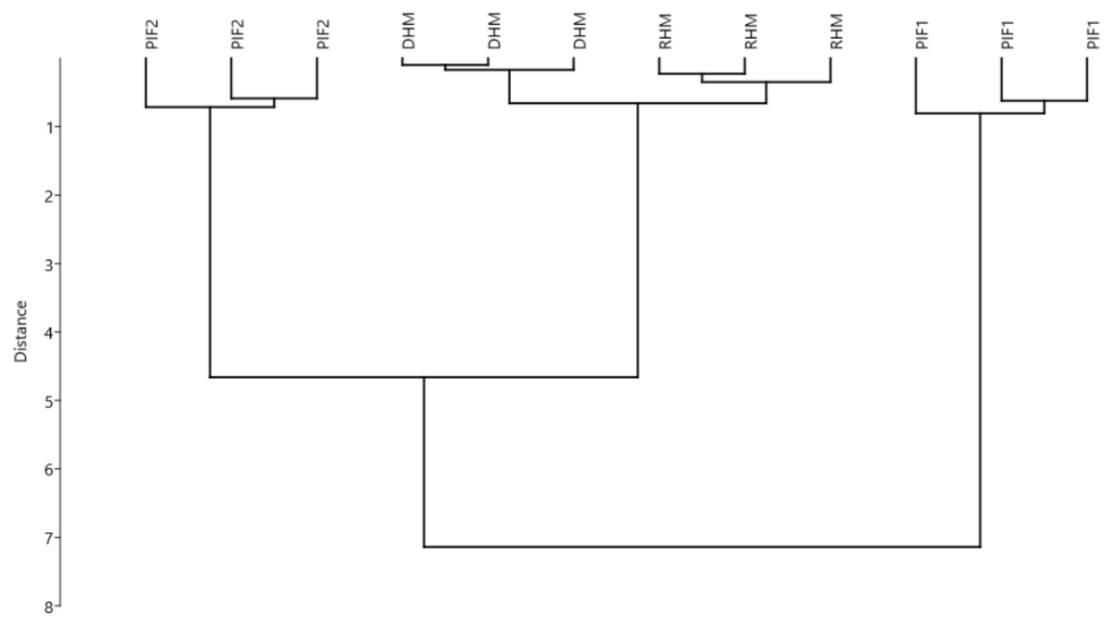

Figure 1. Multivariate cluster analysis (UPGMA algorithm - Manhattan distance) of different preterm infant formula milks (per $100 \mathrm{~mL}$ product). Variables $(n=3)$ : antioxidant capacities (measured as TEAC and DPPH), protein carbonyl and malondialdehyde contents. RHM: raw human milk; DHM: holder pasteurized human milk; PIF1: preterm infant formula type 1; PIF2: preterm infant formula type 2 .

In order to gain a deeper insight, a one-way analysis of variance on the single parameters was performed. Results are reported in Table 2. In accordance with clustering results in Figure 1, human milk samples showed a similar oxidative status, although antioxidant activity as measured by TEAC was higher for pasteurized HM (DHM). In a previous study, Martysiak-Żurowska et al. [35] had found no significant difference $(p \geq 0.05)$ in TEAC between DHM and RHM. In turn, a decreased antioxidant content (carotenoids and tocopherols) has been reported for donor milk with respect to fresh breast milk by other authors [36]. As for human milk substitutes, both PIFs showed a higher content of oxidized compounds, with respect to human milk, in particular for MDA content. 
Table 2. Selected oxidative status indicators (means \pm standard deviations; $n=3$ ) for different preterm foods $(100 \mathrm{~mL})$.

\begin{tabular}{lcccccccc}
\hline & TEAC $^{+}$ & & DPPH $^{+}$ & & PC & & MDA $^{+}$ & \\
\hline RHM & $61.3 \pm 2.2$ & $C$ & $10.8 \pm 0.7$ & $A$ & $0.6 \pm 0.1$ & $A$ & $195 \pm 5$ & $A$ \\
DHM & $82.0 \pm 1.7$ & $B$ & $10.6 \pm 0.2$ & $A$ & $0.9 \pm 0.1$ & $A$ & $199 \pm 6$ & $A$ \\
PIF1 & $10.2 \pm 0.2$ & $D$ & $2.2 \pm 0.3$ & $B$ & $14.3 \pm 2.2$ & $B$ & $1329 \pm 72$ & $C$ \\
PIF2 & $131.7 \pm 3.4$ & $A$ & $2.7 \pm 0.5$ & $B$ & $1.8 \pm 0.2$ & $A$ & $867 \pm 191$ & $B$ \\
\hline
\end{tabular}

TEAC: antioxidant capacity measured as Trolox Equivalents ( $\mu \mathrm{mol})$; DPPH: antioxidant capacity measured as \% inhibition of DPPH radicals; PC: protein carbonyls ( $\mu \mathrm{mol})$; MDA: malondialdehyde (nmol). RHM: raw human milk; DHM: holder pasteurized human milk; PIF1: preterm infant formula type 1; PIF2: preterm infant formula type 2. Significantly different samples are indicated by different italicized letter (A, B, C and D) following the Tukey ( $\dagger$ ) or Dunn's ( $\ddagger)$ post-hoc test $(p<0.05)$.

The formula containing partially hydrolysed proteins (PIF2) showed a significantly lower content in protein carbonyls than the formula containing whole bovine proteins (PIF1). This may be due to the specific PIF2 protein profile, which is represented by $100 \%$ partially hydrolysed whey proteins. Nevertheless, as hydrolysed proteins may escape precipitation by TCA, which is required in sample preparation for PC analysis, we cannot exclude that the carbonyl content of PIF2 is underestimated. PIF1 showed a lower antioxidant capacity with respect to human milk, both measured as TEAC and DPPH, while PIF2 showed a higher TEAC than human milk, probably due to its peculiar peptide composition. It is known that even limited hydrolysis of milk proteins can significantly increase the TEAC of hydrolysates, as compared to parent proteins [37]. Encrypted peptides are able to interact with radical species or to inhibit oxidative reactions thanks the greater exposure of antioxidant amino acids compared to whole proteins [38]. However, it is worth mentioning that, besides protein and peptides, other compounds such as vitamin E, carotenoids and flavonoids could contribute to antioxidant activity in infant formulas [39]. Taking together these characteristics, feeding with PIF2 rather than PIF1 would seem to result in a lower oxidative load for the preterm newborn, although the best choice is always human milk, irrespective of pasteurization. These data confirm those found by other authors by in vivo studies [40-44], who reported higher excretion of oxidised compounds in infants consuming infant formulas, with respect to human milk.

Figure 2 reports the results of multivariate hierarchical clustering of human milk fortifiers and protein concentrate, according to their oxidative status. In this case, three clusters were observed: one represented by DM derived products, one represented by BM based products containing non-hydrolysed proteins, and the last one represented by BM1, which contains highly hydrolysed bovine whey proteins.

Also in this case, MANOVA revealed a significant difference between the samples $(p<0.001)$. In accordance with clustering results, BM1 was significantly different from the other fortifiers for most parameters, and, in particular, it showed a better antioxidant capacity, probably due to the protein content type (100\% extensively hydrolysed whey proteins), as already seen for PIF2 (Table 3). Peptides released from whey proteins during hydrolysis are known to have strong antioxidant activities [45]. Nevertheless, also in this case, the amount of oxidized protein compounds could be underestimated, due to the lack of precipitation for small peptides. Accordingly, the amount of MDA was significantly higher for BM1 than for the non-hydrolysed fortifiers. BM-derived fortifiers (with the exception of BM1) seemed to have lower antioxidant capacities, but also lower MDA and PC contents than donkey milk-derived fortifiers (Table 3). This may be partially due to the fact that the formation of oxidation products, such as PC and MDA, is highly dependent on the amount of reducing sugars and on lipids, which are triggering substrates for oxidation. Both lactose content and lipid content are higher in donkey milk-derived products, accordingly.

One limitation of the present study is that samples were technical replicates of the same batches. In order to generalize our findings, further batches will need to be analysed. 
In general, results suggest that, with the exception of BM1, fortifying human milk result in an increase in the oxidative load. Although few studies are available on the issue, Friel et al. [42] pointed out an elevated urinary excretion of F2-Isoprostenes (an in vivo marker of oxidative stress) for preterm infants who had their mother's milk fortified with bovine-milk based fortifiers, and, recently, the same group confirmed this observation also for infants receiving fortifiers produced by concentrated human milk [46]. Human milk-based fortifiers $[19,20,47]$ were not included in the present study, since they are currently not marketed in Europe. The increased excretion of F2-isoprostanes in preterm infants receiving fortified human milk may also be due to an increased imbalance of antioxidant defences, resulting from the higher protein and macronutrient intake in these infants.

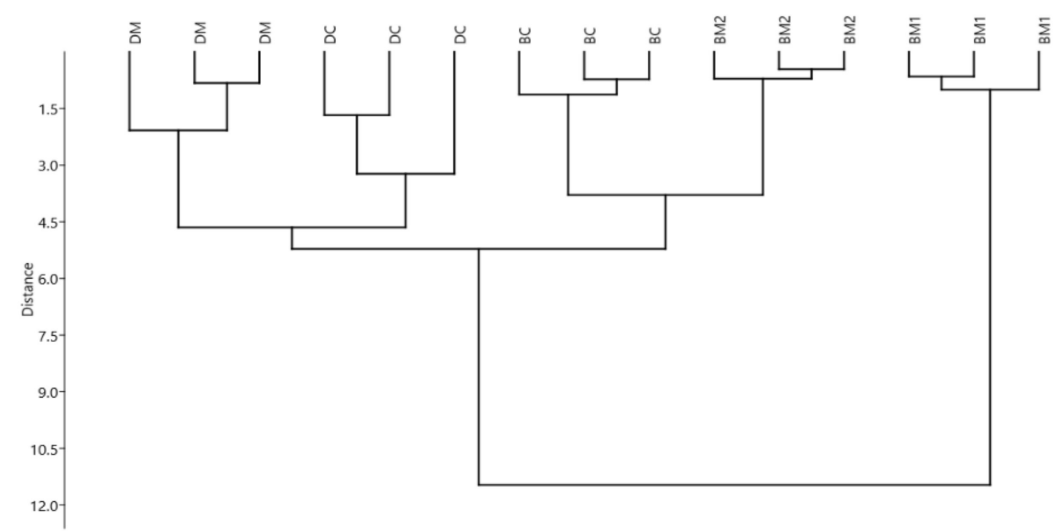

Figure 2. Multivariate cluster analysis (UPGMA algorithm - Manhattan distance) of different human milk fortifiers and protein concentrate (per g of added protein). Variables $(n=3)$ : antioxidant capacities (measured as TEAC, DPPH, and CAA (Cellular antioxidant activity)), haemolysis, protein carbonyl and malondialdehyde contents. BM1: bovine milk preterm fortifier type 1; BM2: bovine milk preterm fortifier type 2; DM: donkey milk preterm fortifier; DC: donkey milk preterm concentrate; BC: bovine milk concentrate.

Table 3. Selected oxidative status indicators (means \pm standard deviations; $n=3$ ) for different human milk fortifiers or protein concentrates (per g of added protein).

\begin{tabular}{|c|c|c|c|c|c|c|c|c|c|c|c|c|}
\hline \multirow[b]{2}{*}{ BM1 } & \multicolumn{2}{|c|}{ TEAC $^{\dagger}$} & \multicolumn{2}{|c|}{$\mathrm{DPPH}^{\dagger}$} & \multicolumn{2}{|c|}{ Haemolisis $\ddagger$} & \multicolumn{2}{|c|}{$\mathrm{CAA}^{+}$} & \multicolumn{2}{|l|}{ PC $\ddagger$} & \multicolumn{2}{|c|}{$\operatorname{MDA}^{\dagger}$} \\
\hline & $470 \pm 4$ & $A$ & $9.6 \pm 0.1$ & $A$ & $11 \pm 1$ & $A$ & $83 \pm 3$ & $A$ & $0.13 \pm 0.05$ & $A$ & $95 \pm 12$ & $A$ \\
\hline BM2 & $37 \pm 0$ & $E$ & $<0.3$ & & $29 \pm 1$ & $A B$ & $41 \pm 3$ & $B$ & $0.56 \pm 0.08$ & $A B$ & $14 \pm 2$ & C \\
\hline BC & $141 \pm 2$ & $C$ & $0.3 \pm 0.1$ & $B$ & $62 \pm 6$ & $B$ & $19 \pm 1$ & $D$ & $0.55 \pm 0.13$ & $A B$ & $10 \pm 2$ & C \\
\hline DM & $113 \pm 2$ & $D$ & $<0.3$ & & $30 \pm 4$ & $A B$ & $33 \pm 3$ & C & $0.81 \pm 0.18$ & $B$ & $92 \pm 7$ & A \\
\hline DC & $193 \pm 2$ & $B$ & $<0.3$ & & $54 \pm 20$ & $B$ & $24 \pm 1$ & $D$ & $1.02 \pm 0.24$ & $B$ & $60 \pm 11$ & $B$ \\
\hline
\end{tabular}

TEAC: antioxidant capacity measured as Trolox Equivalents ( $\mu \mathrm{mol})$; DPPH: antioxidant capacity measured as \% inhibition of DPPH radicals; PC: protein carbonyls $(\mu \mathrm{mol})$; MDA: malondialdehyde (nmol); Haemolysis: \% red blood globules haemolysed with respect to AAPH (100\%); CAA: antioxidant capacity (CAA units). BM1: bovine milk preterm fortifier type 1; BM2: bovine milk preterm fortifier type 2; DM: donkey milk preterm fortifier; DC: donkey milk preterm concentrate; $\mathrm{BC}$ : bovine milk concentrate. Significantly different samples are indicated by different italicized letter (A, B, C, D and E) following Tukey ( + ) or Dunn's ( $\ddagger)$ post-hoc test $(p<0.05)$.

\section{Conclusions}

The preterm infant formulas showed higher oxidative loads when compared to human milk. This is especially true as far as MDA is concerned, since the addition of fortifiers to human milk may result in higher MDA content. On the other end, the addition of fortifiers to human milk may increase the antioxidant capacity, although further confirmations are necessary. Among bovine milk proteins, hydrolysed whey proteins provided a higher antioxidant capacity than whole proteins. These results could be a basis for improving the quality of foods and supplements intended for the nutrition of preterm infants. 
Author Contributions: Investigation, L.P., S.C., R.A., L.C. and M.G.; Methodology, L.P., R.R., M.K., S.A. and M.G.; Supervision, R.A., A.C. and L.C.; Writing-Original draft, L.P., S.C. and M.G.

Funding: Part of this research was funded by the "Short Term Mobility 2015" grant program of Consiglio Nazionale delle Ricerche (CNR) to L.P.

Conflicts of Interest: L.C. and A.C. have competing interests since they are the inventors of a patent on the fortifier derived from donkey milk tested in the study (Italian Patent no. n.0001421271 and international patent application no. WO2015056166 (A1)-20,150,423). The remaining authors report no conflicts of interest.

\section{References}

1. Carlson, S.J.; Ziegler, E.E. Nutrient intake and growth of very low birth weight infants. J. Perinatol. 1998, 18, 252-258. [PubMed]

2. De Curtis, M.; Rigo, J. The nutrition of preterm infants. Early Hum. Dev. 2012, 88, S5-S7. [CrossRef] [PubMed]

3. Arslanoglu, S.; Boquien, C.-Y.; King, C.; Lamireau, D.; Tonetto, P.; Barnett, D.; Bertino, E.; Gaya, A.; Gebauer, C.; Grovslien, A.; et al. Fortification of human milk for preterm infants: Update and recommendations of the European Milk Bank Association (EMBA) Working Group on human milk fortification. Front. Pediatr. 2019, 7, 1-14. [CrossRef] [PubMed]

4. Dutta, S.; Singh, B.; Chessell, L.; Wilson, J.; Janes, M.; McDonald, K.; Shahid, S.; Gardner, V.A.; Hjartarson, A.; Purcha, M.; et al. Guidelines for feeding very low birthweight infants. Nutrients 2015, 7, 423-442. [CrossRef] [PubMed]

5. Embleton, N.E.; Pang, N.; Cooke, R.J. Postnatal malnutrition and growth retardation: An inevitable consequence of current recommendations in preterm infants? Pediatrics 2001, 107, 270-273. [CrossRef] [PubMed]

6. Heird, W.C. Determination of nutritional requirements in preterm infants, with special reference to 'catch-up' growth. Semin. Neonatol. 2001, 6, 365-375. [CrossRef]

7. Horbar, J.D.; Ehrenkranz, R.A.; Badger, G.J.; Edwards, E.M.; Morrow, K.A.; Soll, R.F.; Buzas, J.S.; Bertino, E.; Gagliardi, L.; Bellu, R. Weight growth velocity and postnatal growth failure in infants 501 to 1500 grams: 2000-2013. Pediatrics 2015, 136, e84-e92. [CrossRef]

8. Królczyk, J.B.; Dawidziuk, T.; Janiszewska-Turak, E.; Sołowiej, B. Use of whey and whey preparations in the food industry-A review. Polish J. Food Nutr. Sci. 2016, 66, 157-165. [CrossRef]

9. Lapillonne, A.; Groh-Wargo, S.; Lozano Gonzalez, C.H. Lipid needs of preterm infants: Updated recommendations. J. Pediatr. 2013, 162, S37-S47. [CrossRef]

10. Koo, W.; Tice, H. Human milk fortifiers do not meet the current recommendation for nutrients in very low birth weight infants. J. Parenter. Enter. Nutr. 2018, 42, 813-820. [CrossRef]

11. Fenaille, F.; Parisod, V.; Visani, P.; Populaire, S.; Tabet, J.-C.; Guy, P.A. Modifications of milk constituents during processing: A preliminary benchmarking study. Int. Dairy J. 2006, 16, 728-739. [CrossRef]

12. Pischetsrieder, M.; Henle, T. Glycation products in infant formulas: Chemical, analytical and physiological aspects. Amino Acids 2012, 42, 1111-1118. [CrossRef] [PubMed]

13. Scheidegger, D.; Radici, P.M.; Vergara-Roig, V.A.; Bosio, N.S.; Pesce, S.F.; Pecora, R.P.; Romano, J.C.P.; Kivatinitz, S.C. Evaluation of milk powder quality by protein oxidative modifications. J. Dairy Sci. 2013, 96, 3414-3423. [CrossRef] [PubMed]

14. Inayat, M.; Bany-Mohammed, F.; Valencia, A.; Tay, C.; Jacinto, J.; Aranda, J.V.; Beharry, K.D. Antioxidants and biomarkers of oxidative stress in preterm infants with symptomatic patent ductus arteriosus. Am. J. Perinatol. 2015, 32, 895-904. [CrossRef] [PubMed]

15. Moore, T.A.; Ahmad, I.M.; Zimmerman, M.C. Oxidative stress and preterm birth: An integrative review. Biol. Res. Nurs. 2018, 20, 497-512. [CrossRef] [PubMed]

16. Cháfer-Pericás, C.; Rahkonen, L.; Sánchez-Illana, A.; Kuligowski, J.; Torres-Cuevas, I.; Cernada, M.; Cubells, E.; Nuñez-Ramiro, A.; Andersson, S.; Vento, M.; et al. Ultra high performance liquid chromatography coupled to tandem mass spectrometry determination of lipid peroxidation biomarkers in newborn serum samples. Anal. Chim. Acta 2015, 886, 214-220. [CrossRef] [PubMed] 
17. Hsiao, C.C.; Chang, J.C.; Tsao, L.Y.; Yang, R.C.; Chen, H.N.; Lee, C.H.; Lin, C.Y.; Tsai, Y.G. Correlates of elevated interleukin-6 and 8-hydroxy-2'-deoxyguanosine levels in tracheal aspirates from very low birth weight infants who develop bronchopulmonary dysplasia. Pediatr. Neonatol. 2017, 58, 63-69. [CrossRef] [PubMed]

18. Slater, L.; Asmerom, Y.; Boskovic, D.S.; Bahjri, K.; Plank, M.S.; Angeles, K.R.; Phillips, R.; Deming, D.; Ashwal, S.; Hougland, K.; et al. Procedural pain and oxidative stress in premature neonates. J. Pain 2012, 13, 590-597. [CrossRef] [PubMed]

19. Sandhu, A.; Fast, S.; Bonnar, K.; Baier, R.J.; Narvey, M. Human-based human milk fortifier as rescue therapy in very low birth weight infants demonstrating intolerance to bovine-based human milk fortifier. Breastfeed. Med. 2017, 12, 570-573. [CrossRef] [PubMed]

20. Sullivan, S.; Schanler, R.J.; Kim, J.H.; Patel, A.L.; Trawöger, R.; Kiechl-Kohlendorfer, U.; Chan, G.M.; Blanco, C.L.; Abrams, S.; Cotten, C.M.; et al. An Exclusively human milk-based diet is associated with a lower rate of necrotizing enterocolitis than a diet of human milk and bovine milk-based products. J. Pediatr. 2010, 156, 562-567.e1. [CrossRef]

21. Bertino, E.; Cavallarin, L.; Cresi, F.; Tonetto, P.; Peila, C.; Ansaldi, G.; Raia, M.; Varalda, A.; Giribaldi, M.; Conti, A.; et al. A Novel donkey milk-derived human milk fortifier in feeding preterm infants: A randomized controlled trial. J. Pediatr. Gastroenterol. Nutr. 2019, 68, 116-123. [CrossRef] [PubMed]

22. Coscia, A.; Bertino, E.; Tonetto, P.; Peila, C.; Cresi, F.; Arslanoglu, S.; Moro, G.E.; Spada, E.; Milani, S.; Giribaldi, M.; et al. Nutritional adequacy of a novel human milk fortifier from donkey milk in feeding preterm infants: Study protocol of a randomized controlled clinical trial. Nutr. J. 2018, 17, 1-7. [CrossRef] [PubMed]

23. Martysiak-Żurowska, D.; Puta, M.; Rodzik, A.; Malinowska-Pańczyk, E. The effect of lyophilization on selected biologically active components (vitamin c, catalase, lysozyme), total antioxidant capacity and lipid oxidation in human milk. Żywność. Nauk. Technol. Jakość 2017, 3, 121-128.

24. Salcedo, J.; Gormaz, M.; López-Mendoza, M.C.; Nogarotto, E.; Silvestre, D. Human milk bactericidal properties: Effect of lyophilization and relation to maternal factors and milk components. J. Pediatr. Gastroenterol. Nutr. 2015, 60, 527-532. [CrossRef] [PubMed]

25. Baldini, M.; Fabietti, F.; Giammarioli, S.; Onori, R.; Orefice, L.; Stacchini, A. Analytical methods used in food chemical control. Rapp. ISTISAN 1996, 96, 34.

26. Re, R.; Pellegrini, N.; Proteggente, A.; Pannala, A.; Yang, M.; Rice-Evans, C. Antioxidant activity applying an improved ABTS radical cation decolorization assay. Free Radic. Biol. Med. 1999, 26, 1231-1237. [CrossRef]

27. Brand-Williams, W.; Cuvelier, M.E.; Berset, C. Use of a free radical method to evaluate antioxidant activity. LWT Food Sci. Technol. 1995, 28, 25-30. [CrossRef]

28. Barros, L.; Ferreira, M.-J.; Queirós, B.; Ferreira, I.C.F.R.; Baptista, P. Total phenols, ascorbic acid, $\beta$-carotene and lycopene in Portuguese wild edible mushrooms and their antioxidant activities. Food Chem. 2007, 103, 413-419. [CrossRef]

29. Levine, R.L.; Garland, D.; Oliver, C.N.; Amici, A.; Climent, I.; Lenz, A.-G.; Ahn, B.-W.; Shaltiel, S.; Stadtman, E.R. Determination of carbonyl content in oxidatively modified proteins. Methods Enzymol. 1990, 186, 464-478. [CrossRef]

30. Seljeskog, E.; Hervig, T.; Mansoor, M.A. A novel HPLC method for the measurement of thiobarbituric acid reactive substances (TBARS). A comparison with a commercially available kit. Clin. Biochem. 2006, 39, 947-954. [CrossRef]

31. Frassinetti, S.; Gabriele, M.; Caltavuturo, L.; Longo, V.; Pucci, L. Antimutagenic and antioxidant activity of a selected lectin-free common bean (Phaseolus vulgaris L.) in two cell-based models. Plant Foods Hum. Nutr. 2015, 70, 35-41. [CrossRef] [PubMed]

32. Wolf, K.L.; Liu, R.H. Cellular Antioxidant Activity (CAA) Assay for Assessing Antioxidants, Foods, and Dietary Supplements. J. Agric. Food Chem. 2007, 55, 8896-8907. [CrossRef] [PubMed]

33. Mikstacka, R.; Rimando, A.M.; Ignatowicz, E. Antioxidant effect of trans-resveratrol, pterostilbene, quercetin and their combinations in human erythrocytes in vitro. Plant Foods Hum. Nutr. 2010, 65, 57-63. [CrossRef] [PubMed]

34. Hammer, Ø.; Harper, D.A.T.; Ryan, P.D. PAST: Paleontological statistics software package for education and data analysis. Palaeontol. Electron. 2001, 4, 9. 
35. Martysiak-Zurowska, D.; Puta, M.; Barczak, N.; Dabrowska, J.; Malinowska-Pańczyk, E.; Kiełbratowska, B.; Kołodziejska, I. Effect of high pressure and sub-zero temperature on total antioxidant capacity and the content of vitamin C, fatty acids and secondary products of lipid oxidation in human milk. Polish J. Food Nutr. Sci. 2017, 67, 117-122. [CrossRef]

36. Hanson, C.; Lyden, E.; Furtado, J.; Van Ormer, M.; Anderson-Berry, A. A comparison of nutritional antioxidant content in breast milk, donor milk, and infant formulas. Nutrients 2016, 8, 681. [CrossRef]

37. Dryáková, A.; Pihlanto, A.; Marnila, P.; Čurda, L.; Korhonen, H.J.T. Antioxidant properties of whey protein hydrolysates as measured by three methods. Eur. Food Res. Technol. 2010, 230, 865-874. [CrossRef]

38. Lamothe, S.; Guérette, C.; Dion, F.; Sabik, H.; Britten, M. Antioxidant activity of milk and polyphenol-rich beverages during simulated gastrointestinal digestion of linseed oil emulsions. Food Res. Int. 2019, 122, 149-156. [CrossRef]

39. Lindmark-Månsson, H.; Åkesson, B. Antioxidative factors in milk. Br. J. Nutr. 2000, 84, 103-110. [CrossRef]

40. Aycicek, A.; Erel, O.; Kocyigit, A.; Selek, S.; Demirkol, M.R. Breast milk provides better antioxidant power than does formula. Nutrition 2006, 22, 616-619. [CrossRef]

41. Chen, Y.; Fantuzzi, G.; Schoeny, M.; Meier, P.; Patel, A.L. High-dose human milk feedings decrease oxidative stress in premature infant. J. Parenter. Enter. Nutr. 2019, 43, 126-132. [CrossRef] [PubMed]

42. Friel, J.K.; Diehl-Jones, B.; Cockell, K.A.; Chiu, A.; Rabanni, R.; Davies, S.S.; Jackson Roberts, L. Evidence of oxidative stress in relation to feeding type during early life in premature infants. Pediatr. Res. 2011, 69, 160-164. [CrossRef] [PubMed]

43. Friel, J.K.; Martin, S.M.; Langdon, M.; Herzberg, G.R.; Buettner, G.R. Milk from mothers of both premature and full-term infants provides better antioxidant protection than does infant formula. Pediatr. Res. 2002, 51, 612-618. [CrossRef]

44. Ledo, A.; Escrig, R.; Brugada, M.; Aguar, M.; Saenz, P.; Vento, M.; Arduini, A.; Asensi, M.A.; Sastre, J. Human milk enhances antioxidant defenses against hydroxyl radical aggression in preterm infants. Am. J. Clin. Nutr. 2009, 89, 210-215. [CrossRef] [PubMed]

45. Mann, B.; Athira, S.; Sharma, R.; Kumar, R.; Sarkar, P. Bioactive peptides from whey proteins. Whey Proteins 2019, 519-547. [CrossRef]

46. Cai, C.; Zhang, Z.; Morales, M.; Wang, Y.; Khafipour, E.; Friel, J. Feeding practice influences gut microbiome composition in very low birth weight preterm infants and the association with oxidative stress: A prospective cohort study. Free Radic. Biol. Med. 2019. [CrossRef] [PubMed]

47. Cristofalo, E.A.; Schanler, R.J.; Blanco, C.L.; Sullivan, S.; Trawoeger, R.; Kiechl-Kohlendorfer, U.; Dudell, G.; Rechtman, D.J.; Lee, M.L.; Lucas, A.; et al. Randomized trial of exclusive human milk versus preterm formula diets in extremely premature infants. J. Pediatr. 2013, 163, 1592-1595.e1. [CrossRef] 